\title{
EDITORIAL
}

\section{Oxygen saturation and pneumonia: a complement to current practice or another burden for the GP?}

See linked article by Bewick et al. on pg 378

\section{Vandana Gupta ${ }^{a}$ \\ *Mark Woodhead ${ }^{\mathrm{b}}$}

a Specialist Registrar in Respiratory Medicine, Manchester Royal Infirmary, Manchester, UK

b Honorary Senior Lecturer, University of Manchester \& Consultant in General \& Respiratory Medicine, Department of Respiratory Medicine, Manchester Royal Infirmary, Manchester, UK

\section{*Correspondence:}

Department of Respiratory Medicine, Manchester Royal Infirmary

Oxford Road

Manchester M13 9WL

UK

Tel: +441612764381

Fax: + 441612764989

E-mail: mark.woodhead@cmft.nhs.uk

7th July 2010
General practitioners (GPs) commonly encounter community acquired pneumonia (CAP). The annual incidence is 5-11 per 1000 adult population. ${ }^{1}$ In the community setting, diagnosis of CAP is largely clinical and does not often include use of a chest radiograph - in comparison with diagnosis of CAP in the hospital setting. The differentiation of CAP from other much more common, non-pneumonic respiratory tract illnesses can therefore be difficult especially in the presence of other co-morbidities.

Once diagnosed, severity assessment of CAP is vital to guide whether hospital admission is necessary, and in turn this has major implications for the level of treatment as well as the costs involved. The CRB-65 score is currently the recommended evidence-based severity assessment tool for use out of hospital to support clinical judgement. The CRB-65 score relies on the use of clinical factors (confusion, respiratory rate, blood pressure and age) ${ }^{2}$ but does not include oxygen saturation $\left(\mathrm{SpO}_{2}\right)$. In the hospital setting pulse oximetry should always be used to assess oxygenation in CAP patients; oximetry has also been recommended for use in the community, ${ }^{3}$ although there is limited data to support this. Oxygen saturations $<94 \%$ are a poor prognostic feature and also an indication for oxygen therapy, ${ }_{1}^{4}$ thereby necessitating hospital admission. A North American study showed that $10 \%$ of patients treated out of hospital for CAP were hypoxic, even without risk factors. ${ }^{5}$ A case control study of acutely ill Nursing Home residents demonstrated that a decrease in $\mathrm{SpO}_{2}>3 \%$ was a strong indicator of CAP.

So is pulse oximetry useful in the assessment of patients in the community with CAP? Bewick et al., in their paper published in this issue of the $P C R J,{ }^{7}$ set out to try to answer this question. Their study - a prospective cohort study of 832 consecutive patients admitted to a UK teaching hospital - included the investigation of different oxygenation thresholds, subgroup analysis (e.g. young patients), and interaction with current severity assessment. Patients needed to fulfil diagnostic criteria for CAP including CXR changes to be eligible for inclusion. $\mathrm{SpO}_{2}$ levels with the fraction of inspired oxygen $\left(\mathrm{FiO}_{2}\right)$ were recorded. The primary endpoint was the combination of inpatient mortality within 30 days of admission or admission to critical care. Length of hospital stay and need for mechanical ventilation were secondary endpoints. The 467 out of 832 who had $\mathrm{SpO}_{2}$ measured on room air were studied further. The mean age of the patients was $66.7( \pm 20.1$ SD) years and 30-day inpatient mortality was $10.3 \%$. $\mathrm{SpO}_{2}$ was found to be inversely associated with the combined outcome of 30-day mortality and critical care admission (per unit decrease in $\mathrm{SpO}_{2}$ odds ratio 1.09, $\mathrm{Cl} 1.05-1.14 \mathrm{p}<0.001$ ), even after adjustment for disease severity. $\mathrm{SpO}_{2}$ $\leq 90 \%$ was chosen for further analysis, and was found to be a predictor of mortality or critical care admission in patients $<50$ years and in patients with asthma. However, it was less reliable in patients from nursing homes and in patients with chronic obstructive pulmonary disease (COPD). The authors conclude that pulse oximetry should be used as an adjunct to CRB-65 scoring in the community and that $\mathrm{SpO}_{2} \leq 90 \%$ has good specificity but low sensitivity for predicting adverse outcomes.

On a positive note, this is the first large study to assess the role of $\mathrm{SpO}_{2}$ in managing CAP in the community setting. The study does include a large number of consecutive patients and inpatient mortality was found to be $10.3 \%$, similar to that found in 
epidemiological studies (5.7-14\%). ${ }^{8}$ Therefore, the population is representative of typical hospital admissions with CAP. Furthermore, the authors have shown a clear association between $\mathrm{SpO}_{2}$ on admission and 30-day mortality and critical care admission.

However, the study ${ }^{7}$ was based exclusively on patients admitted to hospital - both via the GP and through the Accident and Emergency (A \& E) department - with radiographic changes consistent with pneumonia, a point also conceded by the authors. This is a well defined and clearly characterised population, but it is not necessarily representative of the population of patients usually seen by GPs in the community. The inclusion of direct $A \& E$ admissions may add a group of more severely ill patients than those usually seen by the GP, and the large group of non-pneumonic respiratory infections (who may or may not have CAP but who are seen by the GP) are excluded. Also, 365 out of 832 patients who had their $\mathrm{SpO}_{2}$ measured after prior oxygen therapy were excluded, a rather large number of exclusions who may have had different characteristics to the included population, thus leading to potential bias. The use of a combined primary endpoint of 30-day mortality and critical care admission is also questionable: different factors would determine these two outcomes. Another drawback is that the authors conclude that $\mathrm{SpO}_{2} \leq 90 \%$ is less useful in Nursing Home residents or COPD patients (a group rather underrepresented in the study, comprising only $17.8 \%$ of cases), which are often the most difficult groups to assess out of hospital. Finally, $\mathrm{SpO}_{2} \leq$ or $\geq 90 \%$ did not significantly improve area under the curve of the receiveroperating curve (ROC) for CRB-65 in predicting 30-day inpatient mortality. This seems odd given the previous conclusions that $\mathrm{SpO}_{2}$ has a clear association with 30-day mortality even after adjustment for disease severity.

Bewick et al.'s study ${ }^{7}$ highlights an important problem for GPs: the difficulty in diagnosing and assessing patients in the community with CAP. Patients often present with cough and other non-specific symptoms where the diagnosis varies from viral bronchitis to CAP. GPs generally do not have the benefit of chest radiographs to confirm consolidation and must make a clinical diagnosis and severity assessment without a precise diagnosis. Indeed in a study of young pneumonia deaths, where three quarters had been seen by a GP for that illness, few had had a diagnosis of CAP made by the GP. ${ }^{9}$ Maybe making a diagnosis is less important than assessment of severity in what is otherwise recognised to be a respiratory infection of some sort? If this is the case then a focussed study on definite CAP such as Bewick and colleagues' will not answer the question about the added value of $\mathrm{SpO}_{2}$ in a general practice setting.

Arterial blood gas measurement is the gold standard in assessing oxygenation. However, it is painful, time consuming and invasive. Pulse oximetry is commonly used in the hospital setting and has been referred to as "the fifth vital sign" in adults and children. ${ }^{10}$ It is becoming increasingly available for GPs and is non-invasive, user friendly and relatively non-expensive. Importantly it is not without limitations, being inaccurate in low perfusion states, dyshaemoglobinaemias, or when the patient is moving. Furthermore there is evidence to suggest that some clinicians have a poor understanding of how oximetry works and how to interpret its results. ${ }^{11}$ This is important in general practice where the proportion of severely ill patients is likely to be significantly less than in this study so false positive results will be of much greater significance.

Pulse oximetry in the community is used in conditions other than CAP. It has been suggested as a way of diagnosing diabetic peripheral arterial disease, ${ }^{12}$ screening for congenital heart disease in children, ${ }^{13}$ and predicting mortality in patients with pulmonary embolus. ${ }^{14}$ In COPD patients an $\mathrm{SpO}_{2}$ value $\leq 92 \%$ is recommended as the cut-off for screening patients for long term oxygen therapy especially if there is evidence of cor pulmonale, cyanosis or if the $\mathrm{FEV}_{1}$ is $<50 \%$ predicted. ${ }^{15} \mathrm{SpO}_{2}<92 \%$ in acute asthma indicates life threatening disease and is a criterion for urgent hospital admission. ${ }^{16}$ A Dutch study of family practitioners reported that oximetry is most valued in assessing patients with acute dyspnoea, patients with known respiratory failure and in patients with COPD. ${ }^{17}$

Bewick and colleagues' study shows an inverse relationship between $\mathrm{SpO}_{2}$ and the primary outcome in this population, but there are significant limitations to the study and we cannot yet say whether these results are applicable to non-hospitalised patients with CAP. However, the study certainly provides a strong basis for further research into this topic. Ideally, as suggested by the authors, a randomised control trial should be performed in the community to clarify this issue further. The authors were dismissive of the practicality of such a study, and if the same, albeit robust, endpoints were used this is certainly the case. However, there is no reason why studies with (albeit softer) endpoints of more relevance to general practice (e.g. hospital admission frequency) could not be performed, and such a study could then be of smaller scale.

What then is the role of pulse oximetry in the community in patients with CAP? For now, clinical judgement supplemented by the CRB-65 score should remain the severity assessment tool of choice for adults with suspected CAP in general practice. The wording of the current CAP Guideline recommendation that 'pulse oximetry, with appropriate training, should be available to GPs...'18 remains appropriate and should not yet be strengthened. What is clear is that further studies of the role of oxygen saturation measurement are needed in patients presenting with suspected CAP in the community.

\section{Conflict of interest declaration}

None declared.

\section{References}

1. Woodhead MA, Macfarlane JT, McCracken JS et al. Prospective study of the aetiology and outcome of pneumonia in the community. Lancet 1987;1:671-4. http://dx.doi.org/10.1016/S0140-6736(87)90430-2

2. Lim WS, van der Eerden MM, Laing $R$ et al. Defining community acquired pneumonia severity on presentation to hospital: an international derivation and validation study. Thorax 2003;58:377-82. http://dx.doi.org/10.1136/ thorax.58.5.377

3. Lim WS, Baudouin SV, George RC et al. BTS guidelines for the management of community acquired pneumonia in adults: update 2009. Thorax 2009;64(Suppl III):iii1-iii55. http://dx.doi.org/10.1136/thx.2009.121434 
4. O'Driscoll BR, Howard LS, Davison AG. BTS guideline for emergency oxygen use in adult patients. Thorax 2008;63(Suppl VI):vi1-vi73. http://dx.doi.org/ 10.1136/thx.2008.102947

5. Levin $\mathrm{KP}$, Hanusa BH, Rotondi A et al. Arterial blood gas and pulse oximetry in initial management of patients with community-acquired pneumonia. J Gen Intern Med 2001;16:590-8. http://dx.doi.org/10.1046/j.1525-1497.2001. 016009590.x

6. Kaye KS, Stalam M, Shershen WE et al. Utility of pulse oximeters in diagnosing pneumonia in nursing home residents. Am J Med Sci 2002;324(5):237-42. http://dx.doi.org/10.1097/00000441-200211000-00001

7. Bewick T, Greenwood S, Lim WS. What is the role of pulse oximetry in the assessment of a patient with community-acquired pneumonia in primary care? Prim Care Resp J 2010;19:378-82. http://dx.doi.org/10.4104/pcrj.2010.00049

8. Macfarlane JT, Finch RG, Ward MJ et al. Hospital study of adult community acquired pneumonia. Lancet 1982;2:296-301.

9. Simpson JCG, Macfarlane JT, Watson J et al. A national confidential enquiry into community acquired pneumonia deaths in young adults in England and Wales. Thorax 2000;55:1040-5. http://dx.doi.org/10.1136/thorax.55.12.1040

10. Neff T. Routine oximetry: a fifth vital sign? Chest 1998;94:227. http://dx.doi.org/10.1378/chest.94.2.227a

11. Elliot M. Tate R, Page K. Do clinicians know how to use pulse oximetry? A literature review and clinical implications. Australian Critical Care 2006;19:13944. http://dx.doi.org/10.1016/S1036-7314(06)80027-5
12. Parameswaran GI, Brand K, Dolan J. Pulse oximetry as a potential screening tool for lower extremity arterial disease in asymptomatic patients with diabetes mellitus. Arch Intern Med 2005;165:442-6. http://dx.doi.org/10.1001/ archinte. 165.4.442

13. Arlettaz R, Bauschatz AS, Monkhoff $M$ et al. The contribution of pulse oximetry to the early detection of congenital heart disease in newborns. Eur $J$ Paediatr 2006;165:94-8.

14. Kline JA, Hernandez-Nino J, Newgard CD et al. Use of pulse oximetry to predict in hospital complications in normotensive patients with pulmonary embolus. Am J Med 2003;115:203-08. http://dx.doi.org/10.1016/50002-9343(03) 00328-0

15. National Institute of Clinical Excellence. Chronic Obstructive Pulmonary Disease: Management of chronic obstructive pulmonary disease in adults in primary and secondary care 2010. www. guidance.nice.org.uk.

16. The Scottish Intercollegiate Guidelines Network and British Thoracic Society. British Guideline on the management of asthma 2009. www.sign.ac.uk

17. Schermer $\mathrm{T}$, Leenders $\mathrm{J}$, in't Veen $\mathrm{H}$ et al. Pulse oximetry in family practice: indications and clinical observations in patients with COPD. Family Practice 2009;26:524-31.

18. Levy ML, Le Jeune I, Woodhead MA et al. Primary care summary of the British Thoracic Society Guidelines for the management of community acquired pneumonia in adults; update 2009. Prim Care Resp J 2010;19(1):21-7. http://dx.doi.org/10.4104/pcrj.2010.00014

\section{Available online at http://www.thepcrj.org}

